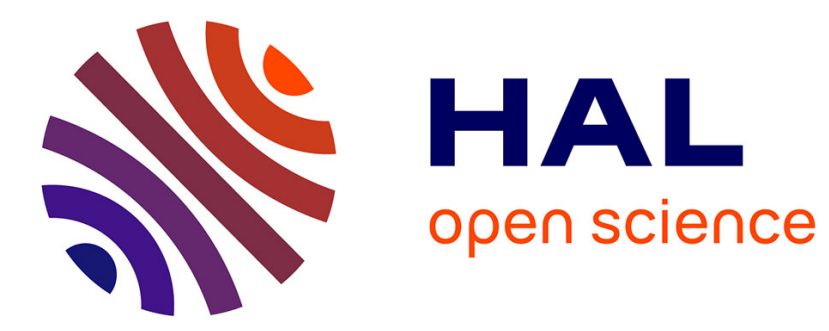

\title{
Temporal Dispersion In Distributed Work
}

Béatrice Linot, Jérôme Dinet, François Charoy, Valerie Shalin

\section{To cite this version:}

Béatrice Linot, Jérôme Dinet, François Charoy, Valerie Shalin. Temporal Dispersion In Distributed Work. IEA 2018 - 20th Congress of International Ergonomics Association, Aug 2018, Florence, Italy. halshs-01896434

\section{HAL Id: halshs-01896434 \\ https://shs.hal.science/halshs-01896434}

Submitted on 16 Oct 2018

HAL is a multi-disciplinary open access archive for the deposit and dissemination of scientific research documents, whether they are published or not. The documents may come from teaching and research institutions in France or abroad, or from public or private research centers.
L'archive ouverte pluridisciplinaire HAL, est destinée au dépôt et à la diffusion de documents scientifiques de niveau recherche, publiés ou non, émanant des établissements d'enseignement et de recherche français ou étrangers, des laboratoires publics ou privés. 


\title{
Temporal Dispersion In Distributed Work
}

\author{
Béatrice Linot ${ }^{1,2}$, Jérôme Dinet ${ }^{1}$, François Charoy ${ }^{2}$ and Valerie L. Shalin ${ }^{3}$ \\ ${ }^{1}$ Lorraine University, 2LPN. Nancy 54000, France \\ ${ }^{2}$ Lorraine University, LORIA. Nancy 54000, France \\ ${ }^{3}$ Wright State University, Dayton OH 45435, USA \\ Beatrice.linoteuniv-lorraine.fr
}

\begin{abstract}
Effective communication is critical to sociotechnical systems. Such systems may entail distributed authority and responsibility, and physical resources that are not collocated. This is certainly the case in crisis management. To improve communication during crisis management, researchers have tried to enhance the communication technology. However, communication problems persist even in the presence of robust technology. Several studies of communication have examined the consequences of the spatial distribution of operators working on the achievement of a common goal. Yet, few have researchers have investigated the effects of temporal distribution. Drawing on documentation of the Deepwater Horizon Accident in 2010, we select examples to reveal the temporal distribution of events that affect the availability of contextual information across a socio-technical system. We claim that temporal distance, like spatial distance, reduces global awareness and the opportunity to observe the incidental behaviour that renders activities mutually accessible.
\end{abstract}

Keywords: Communication, information sharing, temporal dispersion, distributed work.

\section{Introduction}

\subsection{Spatial Dispersion in Work}

Successful socio-technical systems depend on communication and situation awareness, for example, during response to natural disasters [1]. Communication issues persist even in the presence of functioning communication equipment $[2,3]$. Classical ergonomics has recognized the spatial properties of the work environment [4], including the more recent exploration of communication issues. We claim temporal dispersion has the same effect on communication as spatial dispersion.

Work is often distributed, either because of excessive task demands or separable tasks that require special skills. Each team member holds unique situation awareness [5], which may yet be compatible with the other agents [6]. Salas et al. [7] suggest that teams perform best with a "shared mental model". Shared awareness of the overall 
work process provides context for individual activities [8]. Team member spatial proximity fosters information sharing and friendship $[9,10]$.

Certainly, spatial dispersion interferes with general factors pertaining to group dynamics, such as trust and norms [11]. Spatially proximal team members use voice and behavior to render their current task-specific activities accessible to others [12]. Several negative consequences arise without spatial proximity, such as the reduction of mutual knowledge, difficulty in work coordination and a decline in communication $[13,14,15,16,17,18]$.

To compensate for the spatial distance that occurs in domains such as crisis management, researchers hope to employ technology [19]. However, Olson \& Olson [20] note that communication technology fails to compensate for the effect of spatial distance. Karsenty [21] describes the compensatory verbal behavior in the absence of shared visual context in computer supported collaborative work. Dourish \& Belloti [8] note that the provider of information is not the direct beneficiary, but the beneficiary depends on the sender's intuitions regarding the recipients' context and resulting information requirements. Moreover, the sender controls delivery, restricting recipient access, although the sender may not know what information is required and when.

\subsection{Temporal Dispersion in Work}

To the extent that temporal properties of work have been an ergonomic concern, having enough time to accomplish work is the typical focus, often because subtasks have temporal dependencies [22]. In dynamic situations, when rapid decision-making is required, Endsley [5] notes that situation awareness is "the perception of the elements in the environment within a volume of time and space, the comprehension of their meaning and the projection of their status in the near future", (p. 97). Social psychology portends the challenge of temporally dispersed events, which weakens salience [23]. With increasing temporal distance, people frequently take more risk and feel more confident, [24, 25]. Distant events (both past and future) seem more abstract and stereotypical [23], lacking in the very detail that is required to assure situation awareness. Thus, we claim that with temporal distance, like spatial distance, participants lose global awareness.

\subsection{Methodological Considerations}

The effect of temporal dispersion is difficult and costly to simulate, hampering the effort to obtain relevant performance data [26]. Researchers are rarely present during the response to an unanticipated crisis. However, sometimes a government initiates a post-hoc analysis. This is the case in the 2010 Deepwater Horizon accident involving the explosion of a mobile oil drilling platform at the Macondo site in the Gulf of Mexico $[27,28]$. While response to the unfolding disaster is surely relevant to the communication problem, relevant data also result from investigation of the cause of the accident, yielding extensive video-taped testimony. These provide an unusually detailed, publicly accessible account of the work practice in complex temporally distributed socio-technical systems. In this paper, we use select illustrations of human 
behavior from the Deepwater Horizon accident to reveal a daunting communication task. We argue that temporally distributed work impacts the construction of a global representation of the situation; the actors are not aware of the interdependent relations between their respective activities and therefore do not necessarily "see" the importance of communicating apparently innocuous information.

\section{Deepwater Horizon Explosion}

In the spring of 2010 the Deepwater Horizon oil drilling platform dug an exceptionally deep well in the Gulf of Mexico. British Petroleum (BP), engaged numerous subcontractors to complete drilling operations. Transocean serviced the mobile offshore drilling rig. BP contracted for cementing from Halliburton, well data logging from Sperry Sun, and well and cement logging services from Schlumberger. Drilling began at the Macondo site on February 15, 2010, with a targeted March 8, 2010 completion date [28]. However, as shown in Fig. 1, drilling operations (temporary well abandonment) were never completed, terminating instead with the explosion on April 20, 2010 .

February 15, 2010 - Drilling begins on the Deepwater Horizon (owned by Transocean)

February 10, 2010 - Halliburton tests the planned cement blend. They send a suspicious laboratory report to BP on March 8 as an attachment to an email. Halliburton had never reported to BP the results of similarly suspicious test results conducted earlier in February.

April 1, 2010 - Debate arises within BP concerning the type of centralizers to use: "subs" versus "slip-on". However, the supplier (Weatherford) had only 6 of the preferred centralizers in stock.

April 2, 2010 - Like the two February tests that Halliburton ran, the first April test indicated the cement slurry was unstable. Rather than change the composition or alerting BP, Halliburton modified the test conditions to argue for a successful test result.

April 6, 2010 - Government issued permits to BP for well drilling note, "Exercise caution while drilling due to indications of shallow gas and possible water flow."

April 9, 2010 - The remaining $363 \mathrm{~m}$. of drilling requires special casing precautions. Halliburton recommends a type of casing that provides 4 redundant barriers. BP chooses fewer barriers to control cost and time.

April 12, 2010 - A temporary abandonment plan was established to set the cement plug in seawater less than 1,000 feet below the mud line after setting the lockdown sleeve.

April 14, 2010 - The temporary abandonment plan proposed to set the cement plug in mud before displacing the riser with seawater.

April 15, 2010 - Debate arises within Halliburton concerning the number of centralizers that BP plans to use due to the absence of supply. BP recommends optimizing centralizer placement in response to Halliburton objections. Halliburton further recommends extended mud circulation to remove air pockets and debris that can contaminate the cement. BP circulates a fraction of the recommended mud.

April 16, 2010 - Debate concerning the number of centralizers concludes with an e-mail from BP engineer who preferred more centralizers: "But, who cares, it's done, end of story, [we] will probably be fine and we'll get a good cement job."

April 17, 2010 - Deepwater Horizon completes its drilling and the well is being prepared to be cemented so that another rig will retrieve the oil. The blowout preventer is tested and found to be "functional." Halliburton continues to complain that using 6 centralizers "would likely produce channeling and a failure of the cement job."

April 19, 2010 - The plan had morphed into the one set forth in an "Ops Note": the crew would remove 3,300 feet of mud from below the mud line and set the cement plug after the riser had been displaced.

April 19, 2010 - Halliburton completes cementing. 
April 20, 2010 - The "Ops Note" plan prevails: the crew would remove 3,300 feet of mud from below the mud line and set the cement plug after the riser had been displaced.

April 20, 2010 - Explosion following misinterpreted pressure testing.

Fig. 1. Deepwater Horizon event chronology (adapted from Wikipedia [29]).

The investigative commission only notes temporal considerations with respect to cost management. To be sure, serious engineering deficiencies surrounded the blow out preventer, inaccurate diagrams, and ineffectively designed hydraulic shear rams. An automatic shutdown system that should have cut power and hydraulic lines was broken. Though tragic, these outright engineering failures do not concern us here. They are clearly both wrong and remedied with prescribed procedure and organizational culture [30].

Ultimately, investigators associate the failures with communication (see Fig. 2). We note the underlying temporal dispersion which, like spatial dispersion, compromises the human awareness that may compensate for the observed analytic deficiencies. However, these communication failures may resist proceduralized remedy [31]. They may be the unavoidable result of spatio-temporally cross-disciplinary work that is always dependent upon numerous risky judgments and impromptu changes to a previously established plan. Temporally distant operations provide context that is particularly likely to be sequestered. But constant skepticism between experts on an extremely large base rate of non-consequential judgment increases false alarms. The result of false alarms is not merely wasted money; as Endsley [5] noted, dynamical systems, in particular, require timely response.

Fig. 2. Failure of communication between different actors at Macondo [27, 28].

"BP, Transocean, and Halliburton failed to communicate adequately. Information appears to have been excessively compartmentalized at Macondo as a result of poor communication. BP did not share important information with its contractors, or sometimes internally even with members of its own team. Contractors did not share important information with $\mathrm{BP}$ or each other. As a result, individuals often found themselves making critical decisions without a full appreciation for the context in which they were being made (or even without recognition that the decisions were critical)" [27] p. 123.

"BP personnel on the rig were not properly trained and supported, and all three companies failed to communicate key information to people who could have made a difference" [28] p. x.

"Finally, due to poor communication, it does not appear that the men performing and interpreting the test had a full appreciation of the context in which they were performing it. Such an appreciation might have increased their willingness to believe the well was flowing" [27] p. 119.

"Insufficient communication, both prior to and during the final displacement, affected risk awareness and well monitoring on the Deepwater Horizon. BP did not adequately inform Transocean about the risks at the Macondo well, particulary the risks of a poor bottomhole cement job. Transocean argues that if BP had done so, its crew might have demonstrated -heightened awareness" [28] p. 186.

"Transocean and Sperry Drilling personnel did not communicate effectively about the displacement operation. And the BP well site leader did not play a sufficiently active role in ensuring such communication. Communication broke down between the drill crew and the mudloggers on several occasions. [...]. The drill crew repeatedly failed to inform Keith of various activities that influenced well monitoring data. [...]. Keith reported after the explosion that he was concerned that simultaneous activities would complicate monitoring but never expressed those concerns to others. [...]. Even after the Transocean crew shut down the pumps to investigate an anomaly, they did not inform the Sperry Drilling mudlogger, senior Transocean personnel, or the BP well site leader of the anomaly or ask for their help in resolving it” [28] p. 187. 
We have selected a few examples from investigation reports and publicly available testimony of the Deepwater Horizon investigation. Although our methods do not follow anthropologically rigorous grounded theory (i.e., raising an emerging problem by systematic analysis of all the data), we suggest that the illustrations we provide are representative of nominal operations.

\section{The Deviations from the Nominal Plan}

\subsection{The Nominal Plan}

Below we first identify important features of the nominal plan to drill the well and then hand it over to a less costly rig, a process known as abandonment. Then we identify deviations from the nominal plan, which were not appreciated or communicated and combined to create the Deepwater disaster.

Planned operations at the Macondo site included [27]:

1) Centralizers (BP). "When a casing string hangs in the center of the wellbore, cement pumped down the casing will flow evenly back up the annulus, displacing any mud and debris that were previously in that space and leaving a clean column of cement. If the casing is not centered (with centralizers), the cement will flow up the path of least resistance - the larger spaces in the annulus - and slowly or not at all in the narrower annular space. Remaining channels of drilling mud create paths and gaps through which pressurized hydrocarbons can flow", (p. 96).

2) Well drilling and mud circulation (Transocean). Transocean carried out drilling in parallel with the data collection activity carried out by (Sperry Sun). A series of steel tubes protect more fragile sections of the well structure and prevent the entrance of high-pressure fluids (like hydrocarbons) from flowing up the well. Drilling mud cools the drill bit during drilling and plays a critical role in controlling the hydrocarbon pressure in a well. An insufficiently low mud weight allows fluids such as oil and gas to enter the well, causing a "kick." But excessive mud can lead to the leakage of mud into the formation resulting in "lost returns". The rig crew must therefore monitor and adjust the weight of the drilling mud. A proper drilling operation includes a 2,760barrel circulation of drilling mud prior to cementing. Sperry Sun was responsible for the mud data logging at Macondo, (p. 92).

3) Cementing (Halliburton). Crews pump in a specialized cement blend to seal the wellbore. Cement guarantees the watertightness and therefore safety of the well. Proper cement positioning and avoidance of contamination is critical. Drilling mud, cement, and casing strings work together to enable the crew to control wellbore pressure. But the crew cannot directly observe success. Because of the inherent risk, a cement slurry is tested before it is used in a cement job, (p. 99).

4) Negative pressure test (BP \& Transocean). Pressure tests provide indirect indicators of cement integrity and whether it has sealed off the distant well. Pressure and volume readings evaluate whether each barrel of cement pumped into the well displaces an equal volume of drilling mud - producing "full returns." While they suggest generally that the job has gone as planned, they do not assure job quality, (p. 99). 


\subsection{Critical, Temporally Dispersed Deviations}

Given shared general knowledge, awareness of the specific status of the nominal plan, and especially deviations from this plan, constitute the other part of the shared situation awareness concern. But, with Note Deepwater provided spatial proximity: without considering drilling depth where people were not located or multiple rig decks where fewer than 150 people were located, the entire event unfolded within a footprint comparable to a standard soccer field $(112$ x $78 \mathrm{~m})$. But, Deepwater lacked temporal proximity: deviations from the nominal plan occurred not just hours, but some more than weeks before their dire consequence resulted. Had these deviations been communicated, operators might not have missed the warning signals of impending doom. On the other hand, we suspect that changes to the nominal plan always occur because the world never unfolds as planned. The technical problem is identifying $a$ priori those changes that only have consequence in combination with other unanticipated changes.

1) Centralizers (April 1). As shown in Fig. 3, BP used a fewer number of ultimately suboptimal centralizers due to procurement oversights. BP did not inform Halliburton of the number of centralizers it eventually used.

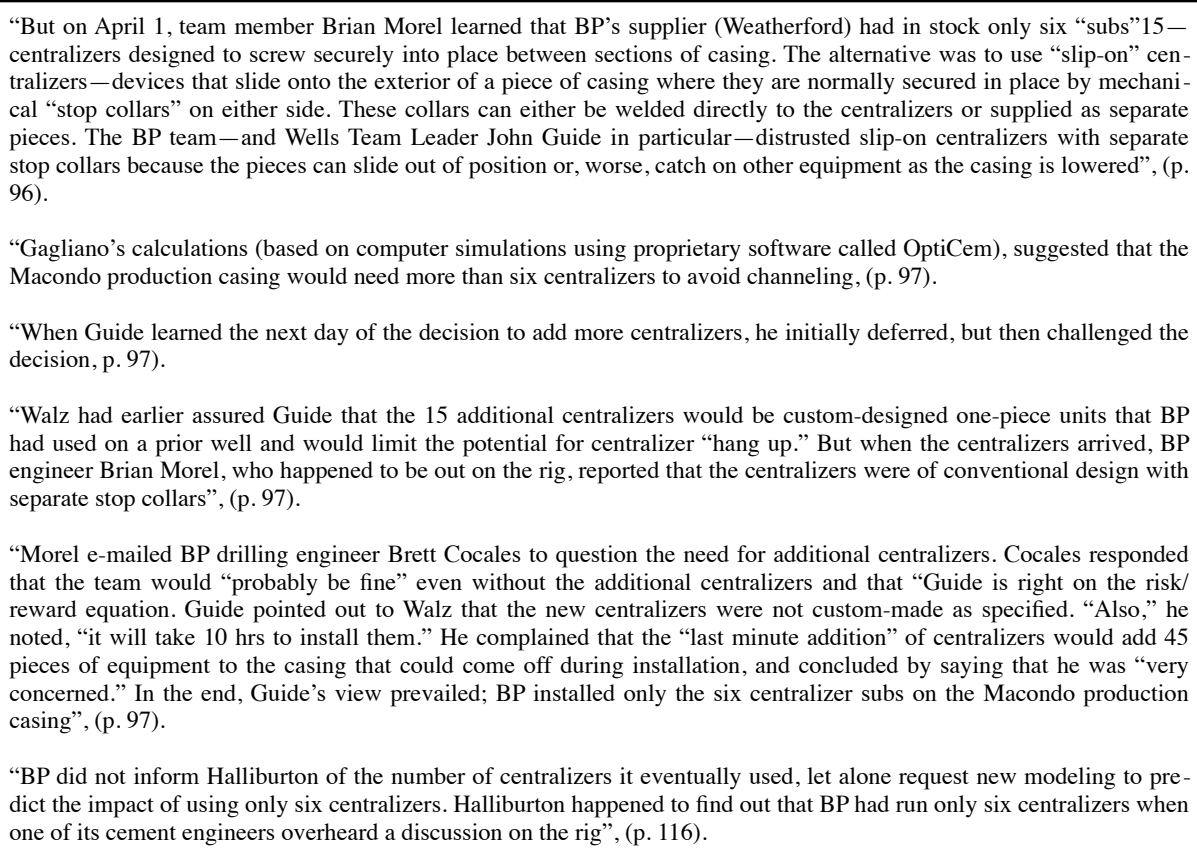

Fig. 3. Rationale concerning the number of centralizers [27].

2) Well drilling and mud circulation (April 9). BP circulated approximately 350 barrels of mud before cementing, in contrast to the recommended 2,760 barrels [28] $\mathrm{p}$. 200. BP engineers feared increased mud circulation risked another lost-return event. 
The decision compromised the integrity of the cement job, and because circulation activity was never communicated, confused the Sperry mudloggers. To compensate, $\mathrm{BP}$ used additional spacer material subsequently, but failed to indicate the corresponding risk increase to Transocean.

3) Cementing (April 2). Halliburton generally flies cement samples from the rig back for laboratory testing to assure compatibility with well conditions. Two tests (in February and April) both indicated that the foam cement slurry would be unstable. Halliburton sent the February 10 laboratory report to BP on March 8 as an attachment to an e-mail. The attachment included the results indicating that the cement was unstable. No evidence suggests that BP examined the attached report. The April test provided similar results, with no evidence that Halliburton specifically alerted BP. Instead, Halliburton personnel modified the pre-testing conditioning time requirements to argue for a successful result. A final test result from April 13 was e-mailed to BP, but again the indications of serious instability was not explicitly communicated [28] p. 130.

4) Negative Pressure Test (April 11). Temporary abandonment procedures were initially specified on April 11 but changed several times including changing the order of steps and at least once omitting the key negative pressure test [28] p. 154. A shoreside team had decided to "deviate" from the testing procedure in the government permit. A subsequently written detailed displacement procedure failed to specify how to interpret the sensor data that accompanied testing. Critically, the April 14 procedures directed that the negative pressure test would be conducted on the kill line. But rig personnel did not follow this instruction during the first negative pressure test. Instead, they conducted the initial negative pressure test on the drill pipe. Ad hoc modifications to the plan contributed to the misinterpretation of the negative pressure test data (see Fig. 4).

\footnotetext{
"In the nine days before BP began the temporary abandonment of the Macondo well, the company went through at least four different versions of temporary abandonment procedures. Each version switched the order of several key steps. In response to the April 12 prodding from Murry Sepulvado, Morel circulated a draft plan for upcoming operations at Macondo later that day. The draft plan included temporary abandonment procedures that instructed the rig crew to set the lockdown sleeve first and then to set a surface cement plug in seawater. The plug would be set just 933 feet below the mudline. Morel's draft did not include a negative pressure test. After reviewing it, well site leader Ronnie Sepulvado reminded Morel that he needed to include a negative pressure test", (p. 131-132).

"Reviewing it, Hafle was concerned that the Ops Note procedure was different than the procedure MMS had approved. Kaluza woke up Morel. Morel explained that the rest of the shoreside team had decided to "deviate" from the procedure in the MMS-approved permit, which called for conducting the negative pressure test before displacement. "The team in town wanted to do something different," Kaluza later explained according to notes of BP's post-blowout interviews. "They decided we could do the displacement and negative test together - don't know why - maybe trying to save time.... Anytime you get behind, they try to speed up", (p. 134).

"For instance, BP originally planned to install the lockdown sleeve at the beginning of the temporary abandonment. BP's decision to change plans and set the lockdown sleeve last triggered a cascade of other decisions that led it to severely underbalance the well while leaving the bottomhole cement as the lone physical barrier in place during displacement of the riser. [...]. Walz admitted that there was "no structured approval process" and that "changes [were] made with email and verbal discussion." Cocales stated that there was "no formal process on communicating changes to [the] well plan." Murry Sepulvado stated that it was not unusual to receive emails like the Ops. Note containing procedural changes that had not been risk assessed through a formal process. And ac-
} 
Fig. 4. Modifications to temporary abandonment procedures [28].

"Beginning April 14, the procedures directed that the negative pressure test would be conducted on the kill line. But rig personnel did not follow this instruction during the first negative pressure test. Instead, they conducted the initial negative pressure test on the drill pipe. This may suggest that in addition to creating better test proce-

Subsequent analysis (see Fig. 5) indicates that decisions surrounding cement operations and centralizers provided context critical for the proper interpretation of an improperly interpreted negative well pressure test. The Chief Counsel's team explains that, "knowledge of ongoing rig activity - is essential to accurate interpretation of the data. Absent that knowledge, it is difficult to ascertain whether anomalous data are benign or problematic", [28] p. 201.

Fig. 5. Pervasive misinterpretation of test results [27].

"The pressure data were not ambiguous. Rather, they showed repeatedly that formation fluids, in this case hydrocarbons, were flowing into the well. The failure to properly conduct and interpret the negative-pressure test was a major contributing factor to the blowout. Given the risk factors surrounding the primary cement job and other prior unusual events (such as difficulty converting the float valves), the BP Well Site Leaders and, to the extent they were aware of the issues, the Transocean crew should have been particularly sensitive to anomalous pressure readings and ready to accept that the primary cement job could have failed. It appears instead they started from the assumption that the well could not be flowing, and kept running tests and coming up with vari-

\section{Conclusions}

In this article, we illustrated temporal dispersion, in which several specialties performing successive activities achieve a common goal. However, a plan never unfolds as initially conceived, requiring the communication of "important" changes between specialists. This did not occur on Deepwater in several key instances. No doubt, latent organizational factors contributed to the communication failures [32]. Our analysis is certainly not intended to justify shoddy engineering or irresponsible profit motives. However, we suspect that the risk of temporal dispersion persists without these organizational factors. A disastrous outcome merely provided an opportunity to observe the risk. The absence of temporal co-location further exemplifies the role that the environment can play in offloading controlled attentional processes [33]. Together, spatial and temporal co-location provide a relevance heuristic for capturing attention automatically, and support behavioral indicators that render activities accessible to others. Without these simultaneous conditions, effortful conceptual association is required to determine relevance.

\section{Acknowledgments}

Valerie Shalin's participation in this project is supported by NSF Grant 1520870 , Srinivasan Parthasarathy Principal Investigator. 


\section{References}

1. Quarantelli, E. L.: Disaster Crisis Management (Preliminary paper \#113). Disaster Research Center, University of Delaware (1986).

2. Lagadec, P.: Le dirigeant et les crises. Administration, revue de l'administration territoriales de l'Etat, $\mathrm{n}^{\circ} 166$ (1995).

3. Dautun, C.: Contribution à l'étude des crises de grande ampleur : connaissance et aide à la décision pour la Sécurité Civile (Doctoral dissertation). Thèse pour obtenir le grade de docteur de l'Ecole Nationale Supérieure des Mines de Saint-Etienne (2007).

4. Van Cott, H.P., Kinkade, R.G.: Human engineering guide to equipment design. Revised ed. Oxford, England: U.S. Government Printing Office (1972).

5. Endsley, M. R.: Design and evaluation for situation awareness enhancement. In Proceedings of the Human Factors and Ergonomics Society Annual Meeting (Vol. 32, No. 2, pp. 97-101). SAGE Publications (1988).

6. Stanton, N. A., Salmon, P. M., Walker, G. H., Jenkins, D.: Genotype and phenotype schemata and their role in distributed situation awareness in collaborative systems. Theoretical Issues in Ergonomics Science, 10(1), 43-68. doi:10.1080/14639220802045199 (2009).

7. Salas, E., Cooke, N. J., Rosen, M. A.: On teams, teamwork, and team performance: Discoveries and developments. Human Factors: The Journal of the Human Factors and Ergonomics Society, 50(3), 540-547 (2008).

8. Dourish, P., Bellotti, V.: Awareness and Coordination in Shared Workspaces. Proceedings of the Conference on Computer-Supported Cooperative Work, Toronto, pp. 107-114 (1992).

9. Monge, P., Rothman, L., Eisenberg, E., Miller, K., Kirste K.: The dynamics of organizational proximity. Management Sci. 31(9) 1129-1141 (1985).

10. Van den Bulte, C., Moenaert, R.: The effects of R\&D team co-location on communication patterns among R\&D, marketing, and manufacturing. Management Sci. 44(11) S1-S18 (1998).

11. Forsyth, D. R.: Methodological advances in the study of group dynamics. Group Dynamics: Theory, Research, and Practice, 2(4), 211-212 (1998).

12. Luff, P., Heath, C.: The collaborative production of computer commands in command and control. International Journal of Human-Computer Studies, 52(4), 669-699 (2000).

13. Scott, S.D., Cummings, M.L., Graeber, D.A., Nelson, W.T., Bolia, R.S.: Collaboration Technology in Military Team Operations: Lessons Learned from the Corporate Domain, CCRTS: Command and Control Research and Technology Symposium, San Diego, CA, June (2006).

14. Allen, T. J.: Managing the flow of technology. Cambridge, MA: MIT Press (1977).

15. Cramton, C.: The mutual knowledge problem and its consequences in dispersed collaboration. Organ. Sci. 12(3) 346-371 (2001).

16. Herbsleb, J.D., Mockus, A., Finholt, T.A., \& Grinter, R.E.: Distance, dependencies, and delay in a global collaboration. In Proceedings, ACM Conference on Computer-Supported Cooperative Work, Philadelphia, PA, Dec. 2-7, pp. 319-328 (2000).

17. Kraut, R., Galegher, J., Egido, C.: Tasks and relationships in scientific research collaborations. Human-Computer Interaction, 3, 31-58 (1988).

18. Zahn, G. L.: Face-to-face communication in an office setting: The effects of position, proximity, and exposure. Communication Research, 18(6), 737-754 (1991).

19. Ernstsen, J., Villanger, D., Thomas, H.: Situation Awareness in Disaster Management: A Study of a Norwegian Collaboration Exercise. Universitetet i Oslo (2014).

20. Olson, G.M., Olson, J.S.: Distance matters. Human-Computer Interaction, 15, 139-197 (2000).

21. Karsenty, L.: Cooperative work and shared visual context: An empirical study of comprehension problems in side-by-side and remote help dialogues. Human-Computer Interaction, 14, 283-315 (1999). 
22. Franke, J., Charoy, F., El Khoury, P.: Collaborative Coordination of Activities with Temporal Dependencies. 18th International Conference on Cooperative Information Systems (COOPIS'2010) / OnTheMove (OTM) Conferences, Oct, Crete, Greece (2010).

23. Liberman, N., Sagristano, M., Trope, Y.: The effect of temporal distance on level of mental construal. Journal of Experimental Social Psychology, 38, 523-534 (2002).

24. Gilovich, T., Kerr, M., \& Medvec, V. H.: Effect of temporal perspective on subjective con fidence. Journal of Personality and Social Psychology, 64, 552-560 (1993).

25. Nisan, M.: Dimension of time in relation to choice behavior and achievement orientation. Journal of Personality and Social Psychology, 57, 660-671 (1972).

26. Liu, S., Palen, L.: Spatiotemporal Mashups: A Survey of Current Tools to Inform Next Generation Crisis Support. Proceedings of the 2009 Information Systems for Crisis Response and Management Conference (ISCRAM 2009), Gothenberg, Sweden (2009).

27. National Commission on the BP Deepwater Horizon Oil Spill and Offshore Drilling (2011a), Report to the President, https://cybercemetery.unt.edu/archive/oilspill/ 20121211005728/http:/www.oilspillcommission.gov/sites/default/files/documents/ DEEPWATER_ReporttothePresident_FINAL.pdf. (retrieved December 9, 2017).

28. National Commission on the BP Deepwater Horizon Oil Spill and Offshore Drilling (2011b), Chief Counsel's Report, http://www.iadc.org/archived-2014-osc-report/documents/C21462-407_CCR_for_print_0.pdf (retrieved December 9, 2017).

29. Timeline of the Deepwater Horizon oil spill. From Wikipedia, the free encyclopedia, https://en.wikipedia.org/wiki/Timeline_of_the_Deepwater_Horizon_oil_spill. (Last edited on 2 April (2018)).

30. Sharit, J.: Human error and human reliability analysis. In G. Salvendy (ed). Handbood of Human Factors and Ergonomics (4th ed.) pp. 734-800. John Wiley \& Sons, Inc.: Hoboken (2012).

31. Perrow, C.: Normal Accidents: Living with High Risk Technologies. (Revised edition, 1999). Princeton, NJ: Princeton University Press (1984).

32. Reason, JT.: Human Error. Cambridge, England: Cambridge University Press (1990).

33. Zhang, J., Norman, D.: Representations in distributed cognitive tasks. Cognitive science 18, 87-122 (1994). 